\title{
A re-evaluation of the $\mathrm{ClO} / \mathrm{Cl}_{2} \mathrm{O}_{2}$ equilibrium constant based on stratospheric in-situ observations
}

\author{
M. von Hobe, J.-U. Grooß, R. Müller, S. Hrechanyy, U. Winkler, and F. Stroh \\ Institut für Chemie und Dynamik der Geosphäre I: Stratosphäre (ICG-I), Forschungszentrum Jülich, Jülich, Germany \\ Received: 3 August 2004 - Published in Atmos. Chem. Phys. Discuss.: 7 September 2004 \\ Revised: 14 February 2005 - Accepted: 18 February 2005 - Published: 2 March 2005
}

\begin{abstract}
In-situ measurements of $\mathrm{ClO}$ and its dimer carried out during the SOLVE II/VINTERSOL-EUPLEX and ENVISAT Validation campaigns in the Arctic winter 2003 suggest that the thermal equilibrium between the dimer formation and dissociation is shifted significantly towards the monomer compared to the current JPL 2002 recommendation. Detailed analysis of observations made in thermal equilibrium allowed to re-evaluate the magnitude and temperature dependence of the equilibrium constant. A fit of the JPL format for equilibrium constants yields $K_{E Q}=3.61 \times 10^{-27} \exp (8167 / T)$, but to reconcile the observations made at low temperatures with the existing laboratory studies at room temperature, a modified equation, $K_{E Q}=5.47 \times 10^{-25}(T / 300)^{-2.29} \exp (6969 / T)$, is required. This format can be rationalised by a strong temperature dependence of the reaction enthalpy possibly induced by $\mathrm{Cl}_{2} \mathrm{O}_{2}$ isomerism effects. At stratospheric temperatures, both equations are practically equivalent. Using the equilibrium constant reported here rather than the JPL 2002 recommendation in atmospheric models does not have a large impact on simulated ozone loss. Solely at large zenith angles after sunrise, a small decrease of the ozone loss rate due to the $\mathrm{ClO}$ dimer cycle and an increase due to the $\mathrm{ClO}-\mathrm{BrO}$ cycle (attributed to the enhanced equilibrium $\mathrm{ClO}$ concentrations) is observed, the net effect being a slightly stronger ozone loss rate.
\end{abstract}

\section{Introduction}

$\mathrm{ClO}$ and its dimer $\left(\mathrm{Cl}_{2} \mathrm{O}_{2}\right)$ are the key species involved in the most important ozone destruction cycle in the cold polar winter stratosphere (Molina and Molina, 1987):

$$
\mathrm{ClO}+\mathrm{ClO}+\mathrm{M} \leftrightarrow \mathrm{Cl}_{2} \mathrm{O}_{2}+\mathrm{M} \quad K_{E Q}=k_{f} / k_{b}
$$

Correspondence to: $\mathrm{M}$. von Hobe

(m.von.hobe@fz-juelich.de) with

$$
\begin{aligned}
& K_{E Q}=\left[\mathrm{Cl}_{2} \mathrm{O}_{2}\right] /[\mathrm{ClO}]^{2} \\
& \mathrm{Cl}_{2} \mathrm{O}_{2}+h v \rightarrow \mathrm{Cl}+\mathrm{ClOO} \quad J \\
& \mathrm{ClOO}+\mathrm{M} \rightarrow \mathrm{Cl}+\mathrm{O}_{2}+\mathrm{M} \\
& 2\left(\mathrm{Cl}+\mathrm{O}_{3}\right) \rightarrow 2\left(\mathrm{ClO}+\mathrm{O}_{2}\right)
\end{aligned}
$$

While at small solar zenith angles the forward reaction of (R1) and dimer photolysis (R2) dominate and $k_{f}$ and $J$ control both the partitioning between $\mathrm{ClO}$ and $\mathrm{Cl}_{2} \mathrm{O}_{2}$ and the overall rate of the catalytic cycle, the thermal equilibrium (1) of Reaction (R1) controls the $\mathrm{ClO} / \mathrm{Cl}_{2} \mathrm{O}_{2}$ partitioning at night.

The equilibrium constant $K_{E Q}$ depends inversely on temperature. $K_{E Q}$ has been quantified in numerous laboratory studies (e.g. Cox and Hayman, 1988; Horowitz et al., 1994; Nickolaisen et al., 1994), but all were carried out at temperatures above those prevailing in the stratosphere. The current recommendation (Sander et al., 2003, referred to as JPL 2002 hereafter) extrapolates these studies to stratospheric temperatures. However, substantial evidence exists that this procedure does not yield realistic values for $K_{E Q}$. Higher $\mathrm{ClO}$ concentrations at night than can be explained by the JPL 2002 equilibrium constant have been reported in several studies (Glatthor et al., 2004; Pierson et al., 1999; Ricaud et al., 2004; von Clarmann et al., 1997). Avallone and Toohey (2001) give a lower estimate of $K_{E Q}$ compared to JPL 2002 employing Eq. (1) on field measurements of $\mathrm{ClO}$ and estimated $\mathrm{Cl}_{2} \mathrm{O}_{2}$ concentrations based on the total amount of active chlorine calculated from tracer correlations and assuming total activation. The only previous study based on simultaneous observations of $\mathrm{ClO}$ and $\mathrm{Cl}_{2} \mathrm{O}_{2}$ (Stimpfle et al., 2004) also makes a strong case, that JPL 2002 overestimates $K_{E Q}$ at stratospheric temperatures: night-time observations are reproduced most accurately by models using the

(C) 2005 Author(s). This work is licensed under a Creative Commons License. 


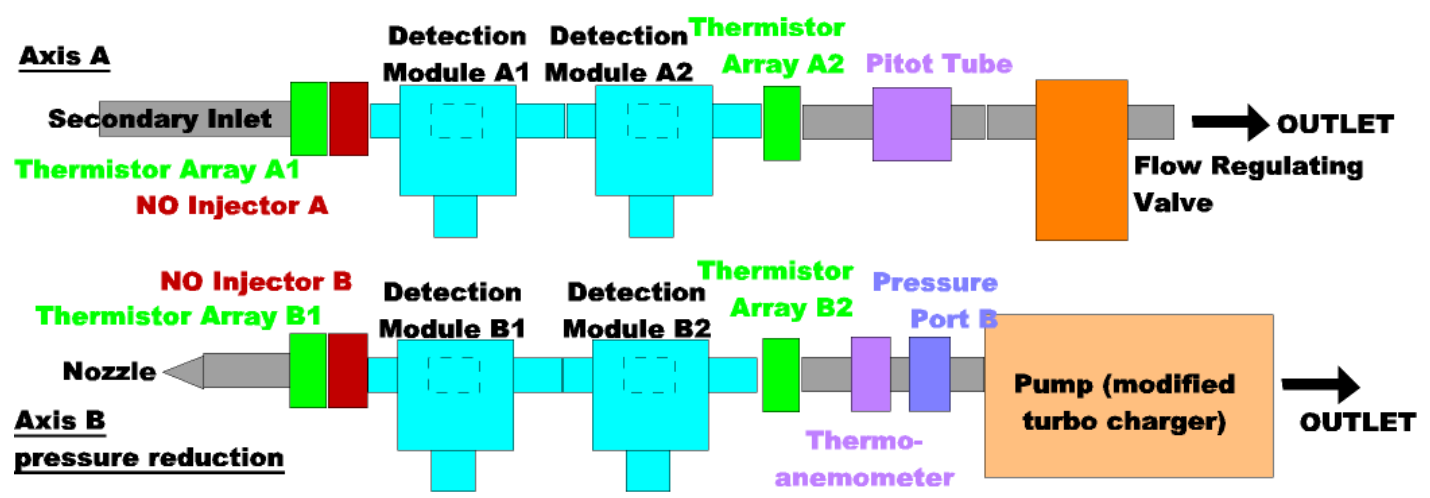

Fig. 1. Outline of the HALOX instrument. Modules A1 and B1 detect chlorine, A2 and B2 bromine.

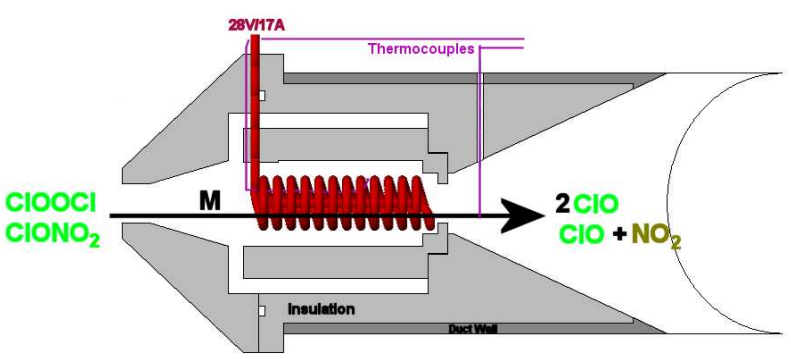

Fig. 2. Schematic of the heated inlet.

Avallone and Toohey estimate (Avallone and Toohey, 2001) for $K_{E Q}$. Finally, a recent laboratory study presented by Plenge et al. (2004b) ${ }^{1}$ using photoionisation mass spectrometry yields a parameterisation giving even lower values for $K_{E Q}$ compared to Avallone and Toohey (2001).

During the Arctic winter 2002/2003, we carried out simultaneous in-situ measurements of $\mathrm{ClO}$ and $\mathrm{Cl}_{2} \mathrm{O}_{2}$. Based on observations made in darkness, we report a new parameterisation for $K_{E Q}$ that lies significantly below JPL 2002 and most other previous studies mentioned above. Possible reasons for these discrepancies are discussed, and an attempt is made to identify possible problems with the extrapolation of the laboratory determinations of $K_{E Q}$ (Cox and Hayman, 1988; Horowitz et al., 1994; Nickolaisen et al., 1994) to stratospheric temperatures, that might explain the discrepancies between $K_{E Q}$ deduced from the observations and the value recommended in JPL 2002. Furthermore, possible implications of the reduced $K_{E Q}$ for the chemistry of the polar stratosphere in general and ozone loss rates in particular are discussed.

\footnotetext{
${ }^{1}$ Plenge, J., Kühl, S., Vogel, B., Müller, R., Stroh, F., von Hobe, M., Flesch, R., and Rühl, E.: Bond strength of the $\mathrm{ClO}$ dimer, J. Phys. Chem., submitted, 2004b.
}

\section{Observations}

Measurements of $\mathrm{ClO}$ and $\mathrm{Cl}_{2} \mathrm{O}_{2}$ were carried out during the SOLVE II/VINTERSOL-EUPLEX and ENVISAT Validation campaigns from January to March 2003, utilising the HALOX instrument situated in a pod under the left wing of the stratospheric research aircraft M55-Geophysica. For the study of the $\mathrm{ClO} / \mathrm{Cl}_{2} \mathrm{O}_{2}$ equilibrium, only observations made under equilibrium conditions (cf. Sect. 3) were used, which include data from six flights carried out between 19 January and 2 March. The temperatures encountered during these flights range from 191 to $212 \mathrm{~K}$.

The HALOX instrument employs the chemical conversion resonance fluorescence (CCRF) technique for measuring $\mathrm{ClO}$ described by Brune et al. (1989). NO is added to the sampled air via needle arrays placed in each measurement duct in order to produce chlorine atoms via the fast reaction $\mathrm{ClO}+\mathrm{NO} \rightarrow \mathrm{Cl}+\mathrm{NO}_{2}$. The chlorine atoms are detected by resonance fluorescence at $118.9 \mathrm{~nm}$, using low pressure gas discharge lamps containing trace amounts of chlorine in $5 \mathrm{hPa}$ helium as light source and VUV photomultiplier tubes (EMR 541J-09-17) as detectors. The NO addition is switched on and off in cycles of 10 to $20 \mathrm{~s}$, and the $\mathrm{ClO}$ concentration is calculated from the ratio of the fluorescence signal to the intensity of the background light scatter, correcting for the $\mathrm{ClO}$ to $\mathrm{Cl}$ conversion efficiency, which is calculated based on $\mathrm{NO}$ and $\mathrm{O}_{3}$ concentrations, flow rate, temperature and pressure using FACSIMILE and is typically about 80 to $90 \%$. As shown in Fig. 1, HALOX consists of two parallel measurement ducts. The open duct $\mathrm{A}$, in which the flow velocity is regulated to within $10-20 \mathrm{~m} \mathrm{~s}^{-1}$ by a butterfly valve (MKS 253B), is used to measure $\mathrm{ClO}$ with a detection limit of $5 \mathrm{ppt}$ and an accuracy of approximately $15 \%$. To improve precision, 3 to $10 \mathrm{NO}$ addition cycles are averaged. Error limits for $[\mathrm{ClO}]$ are computed taking into account accuracy and the standard error resulting from data averaging. In measurement duct $\mathrm{B}$, which is pumped to decrease the pressure inside by about $40 \%$, the sum of $\mathrm{ClO}$ and $\mathrm{Cl}_{2} \mathrm{O}_{2}$ is measured after thermal dissociation of the dimer in a heated inlet nozzle 


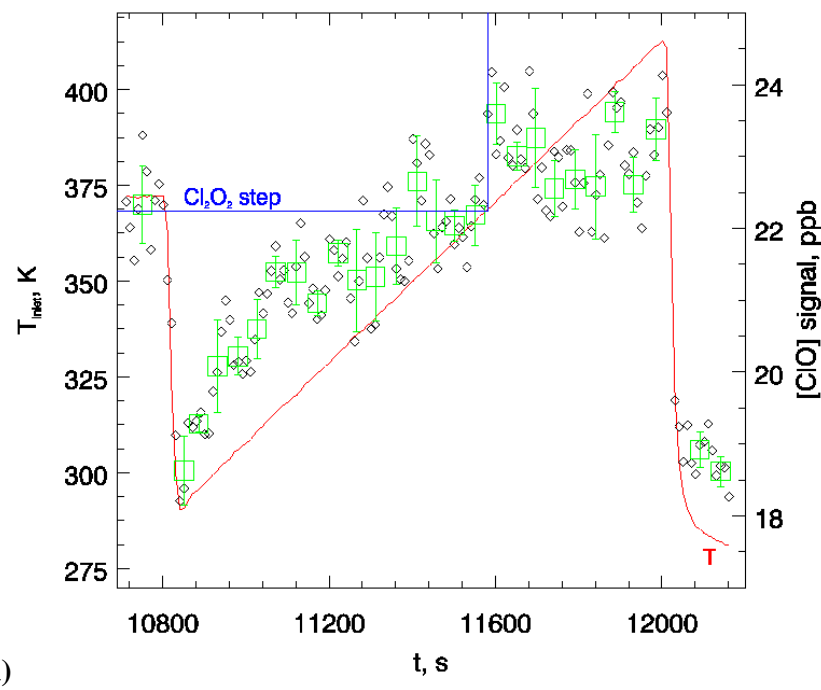

(b)

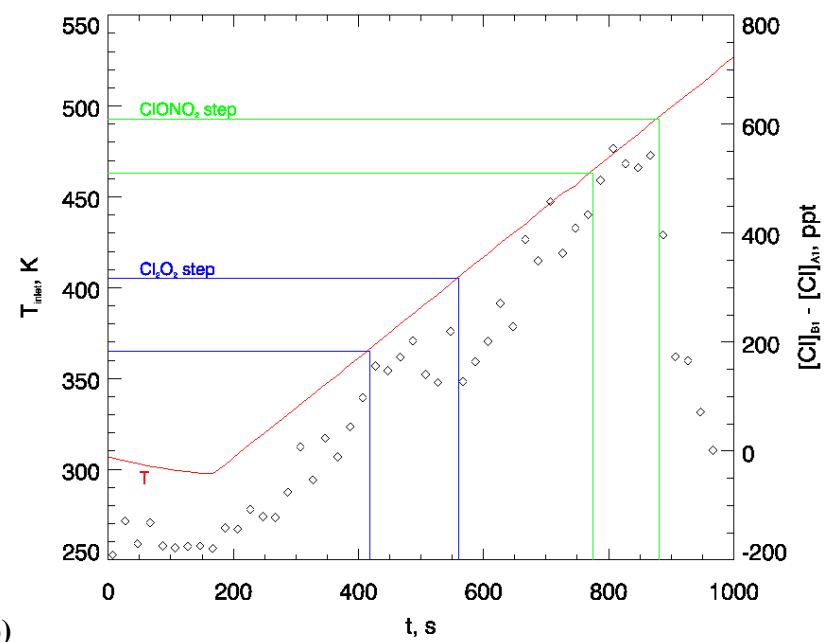

Fig. 3. $\mathrm{ClO}$ concentration from resonance fluorescence signal against inlet temperature for a temperature ramp obtained (a) under laboratory conditions and (b) during a EUPLEX flight on 23 January 2003. Each black diamond represents one individual measurement (i.e. one NO addition cycle); green squares in (a) represent averages over $5 \mathrm{~K}$ temperature intervals, error bars representing $1 \sigma$. Note, that under flight conditions, the natural variability of $\mathrm{ClO}$ and $\mathrm{Cl}_{2} \mathrm{O}_{2}$ does contribute to the signal.

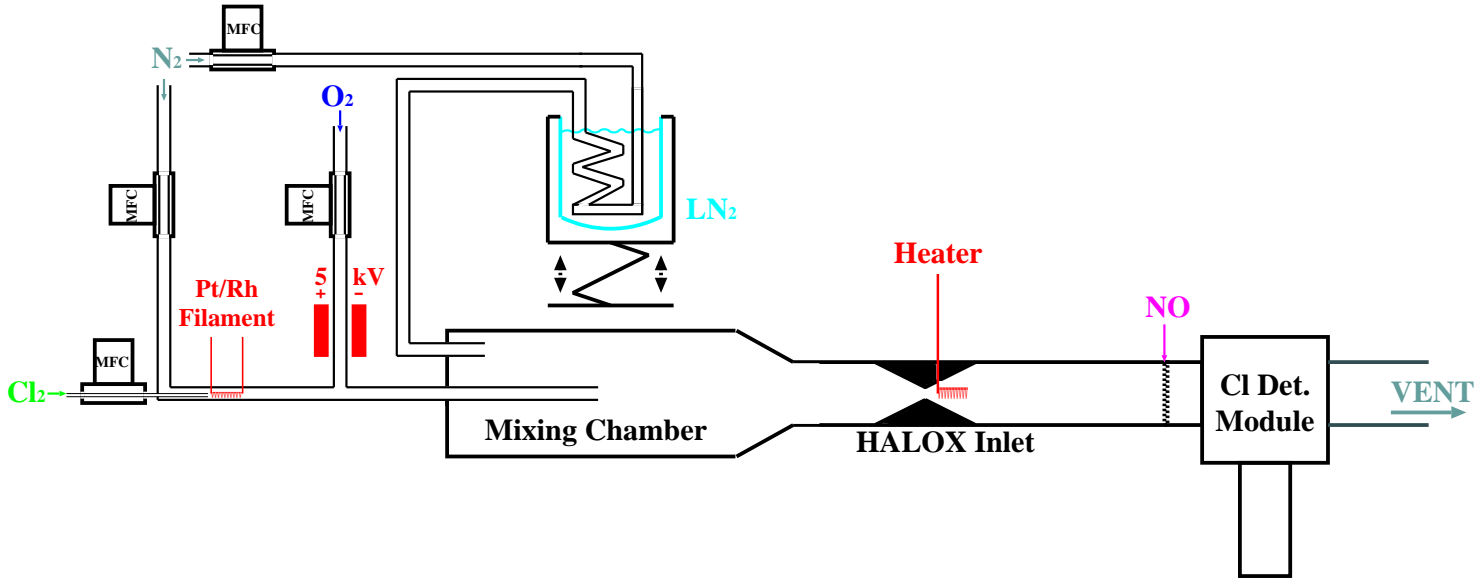

Fig. 4. Set up of the ClO-dimer validation/calibration system. All gas flows are regulated by mass flow controllers (MFCs). Temperatures are measured at the inlet heater, at the NO injector and directly behind the chlorine detection module. Pressure and flow velocity are also measured directly behind the detection module. A butterfly valve placed at the HALOX exhaust regulates the flow to maintain a constant pressure inside the measurement duct.

depicted in Fig. 2. As the temperature, measured by a thermocouple placed behind the inlet, is raised, an increasing amount of $\mathrm{Cl}_{2} \mathrm{O}_{2}$ (if present) dissociates and the signal increases until reaching a constant level at about $370 \mathrm{~K}$ where therefore dimer dissociation may be assumed to be complete, as demonstrated in Fig. 3. Because in this way in duct $\mathrm{B}$ the sum of $2 \mathrm{Cl}_{2} \mathrm{O}_{2}+\mathrm{ClO}$ is measured, to extract the $\mathrm{Cl}_{2} \mathrm{O}_{2}$ concentration present in the atmosphere, the $\mathrm{ClO}$ background has to be subtracted. This is done using the $\mathrm{ClO}$ measurement of duct A, which is compared to the signal in duct $\mathrm{B}$ at regular intervals without heating. $\mathrm{ClO}$ measurements in ducts $\mathrm{A}$ and $\mathrm{B}$ agreed to within 5-10\% indicating that no radicals are lost in the cold nozzle. Small differences $(<20 \%)$ observed during some flights (that could usually be traced to ambiguous lamp calibration parameters) were corrected for by scaling the measurements of the two ducts using average values of simultaneous $\mathrm{ClO}$ measurements. The accuracy of the $\mathrm{Cl}_{2} \mathrm{O}_{2}$ measurement results from the propagation of the accuracies of $\mathrm{A}$ and $\mathrm{B}$ and depends to some extent on the relative amounts of $\mathrm{ClO}$ and $\mathrm{Cl}_{2} \mathrm{O}_{2}$ present. Typically it lies around $20-30 \%$. If the inlet temperature is raised to above $410 \mathrm{~K}$, the $\mathrm{ClO}$ signal starts to increase again due to 


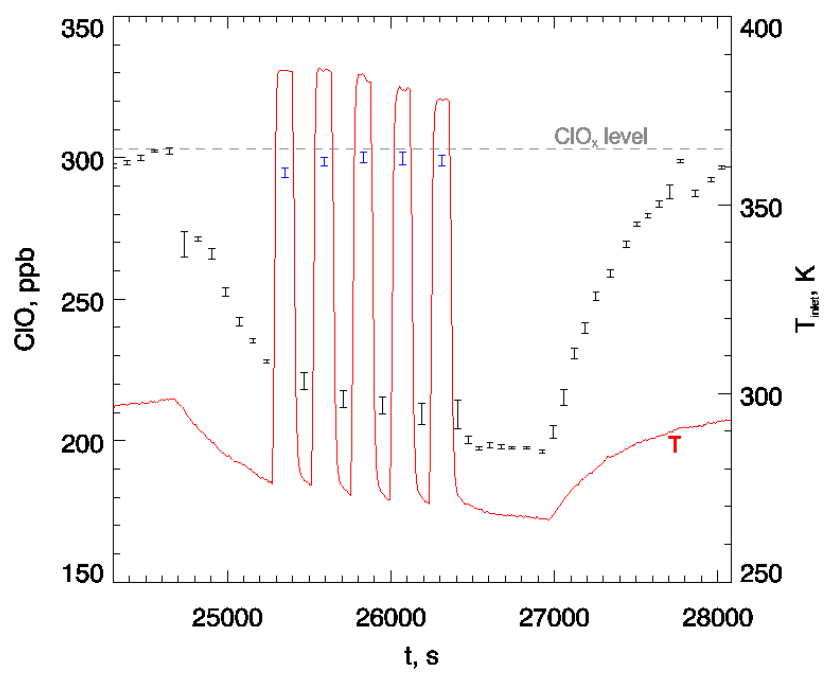

Fig. 5. Laboratory test $\left(P_{\text {duct }}=80 \mathrm{hPa}\right)$ of dimer conversion efficiency of the heated inlet. Error bars represent the standard error of the mean for one minute averages (equivalent to six NO addition cycles), blue colour indicates that the temperature (red line) of the inlet heater was at the dimer dissociation temperature $(363 \mathrm{~K}<T<383 \mathrm{~K})$. The dashed line indicates the reference $\mathrm{ClO}$ concentration measured without cooling or heating.

dissociation of chlorine nitrate, $\mathrm{ClONO}_{2}$ (Fig. 3b). Laboratory tests have shown that less than $1 \%$ of any $\mathrm{ClONO}_{2}$ present dissociates at $390 \mathrm{~K}$, so that an overestimation of the $\mathrm{Cl}_{2} \mathrm{O}_{2}$ concentration due to a possible contribution of $\mathrm{ClONO}_{2}$ can be ruled out unless $\left[\mathrm{ClONO}_{2}\right] \gg\left[\mathrm{Cl}_{2} \mathrm{O}_{2}\right]$. During SOLVE II/VINTERSOL-EUPLEX and the ENVISAT validation campaign, the inlet heater was cycled between the dimer and $\mathrm{ClONO}_{2}$ dissociation temperatures, with occasional periods of no heating to check the consistency between ducts $\mathrm{A}$ and $\mathrm{B}$.

The conversion efficiency of the inlet heater with respect to $\mathrm{Cl}_{2} \mathrm{O}_{2}$ has been tested in the laboratory employing the system shown in Fig. 4. Molecular chlorine (5\% in $\mathrm{He}$ ) is dissociated by an ohmically heated $\mathrm{Pt} / \mathrm{Rh}$ filament, and the chlorine atoms are converted to $\mathrm{ClO}$ by reaction with ozone produced by flowing molecular oxygen gas through a high voltage field. The ozone concentration in the system was monitored by UV spectrophotometer and found to be around $1 \mathrm{ppm}$ at the point of $\mathrm{NO}$ injection. This $\mathrm{ClO}$ source was shown to be stable over the timescales of the experiments (up to $2 \mathrm{~h}$ ). The $\mathrm{ClO}$ is diluted with molecular nitrogen and directed through the unheated inlet into HALOX duct $\mathrm{B}$, which on the exhaust side is connected to a vacuum line containing a butterfly valve (MKS 253B) used to regulate the pressure inside the system. The residence time in the mixing chamber (i.e. between injection of $\mathrm{ClO}$ into the nitrogen gas stream and passage of the inlet heater) in between 0.5 and $1 \mathrm{~s}$. When the nitrogen is cooled by immersing the supply line into a dewar filled with liquid nitrogen, the fluorescence signal pro-

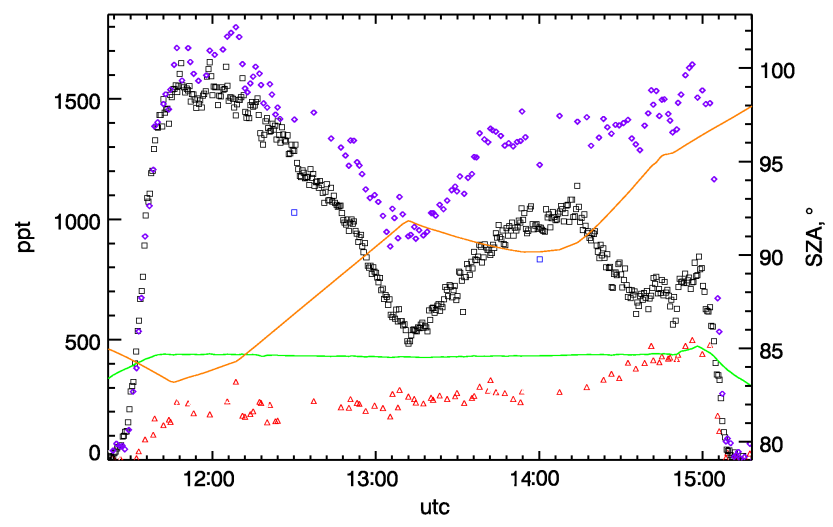

Fig. 6. Time series of $\mathrm{ClO}$ (black squares: duct A, blue squares: duct $\mathrm{B}$ ), $\mathrm{Cl}_{2} \mathrm{O}_{2}$ (red triangles) and $\mathrm{ClO}_{\mathrm{x}}$ (purple diamonds; from duct B) measured on 30 January 2003. Also shown are potential temperature theta (green line) and solar zenith angle (orange line).

duced by the $\mathrm{ClO}$ decreases; when the inlet heater is turned to $100^{\circ} \mathrm{C}$, the fluorescence signal returns quantitatively as illustrated in Fig. 5. We ascribe this to formation of $\mathrm{Cl}_{2} \mathrm{O}_{2}$ upon cooling, and dissociation in the heated inlet. However, a small proportion of $\mathrm{ClO}$ may be removed by wall loss, especially at low pressures and flow rates. Turning the inlet heater on while the calibration gas is not cooled does not affect measured $\mathrm{ClO}$ concentration. The laboratory studies do not suggest any problems with incomplete dimer conversion in the heated inlet. A lower limit for the conversion efficiency is estimated to $80 \%$ based on the accuracy and precision of the laboratory measurements. The combined error limits given for $\left[\mathrm{Cl}_{2} \mathrm{O}_{2}\right]$ measured during the flights incorporate the uncertainty of the conversion efficiency together with the accuracy and the standard error estimated from data averaging. One potential problem detected during the laboratory tests was the release of unknown impurities (probably of organic nature) from one of the thermal insulation materials, which results in quenching of the chlorine radicals in the measurement duct following NO injection. As this effect was only observed at heater coil surface temperatures above $600 \mathrm{~K}$, which were virtually never reached during the $\mathrm{ClO}$ and $\mathrm{Cl}_{2} \mathrm{O}_{2}$ temperature steps, it is not believed to depreciate the $\mathrm{ClO}$ and $\mathrm{Cl}_{2} \mathrm{O}_{2}$ measurements. However, coil temperatures well above $600 \mathrm{~K}$ often existed for the $\mathrm{ClONO}_{2}$ measurements, which explains the sharp drop in signal intensity seen in Fig. $3 \mathrm{~b}$ at inlet temperatures above $480 \mathrm{~K}$. For this reason, a number of $\mathrm{ClO}$ or $\mathrm{Cl}_{2} \mathrm{O}_{2}$ data points following each $\mathrm{ClONO}_{2}$ temperature step was discarded, depending on how far $600 \mathrm{~K}$ was exceeded during the preceding step.

Figure 6 shows the results for an afternoon flight (30 January 2003), in which the same air masses probed on the outbound leg were resampled during the return leg. This flight nicely illustrates, how the $\mathrm{ClO}$ monomer is slowly reacting into the dimer as the solar zenith angle (SZA) increases. 

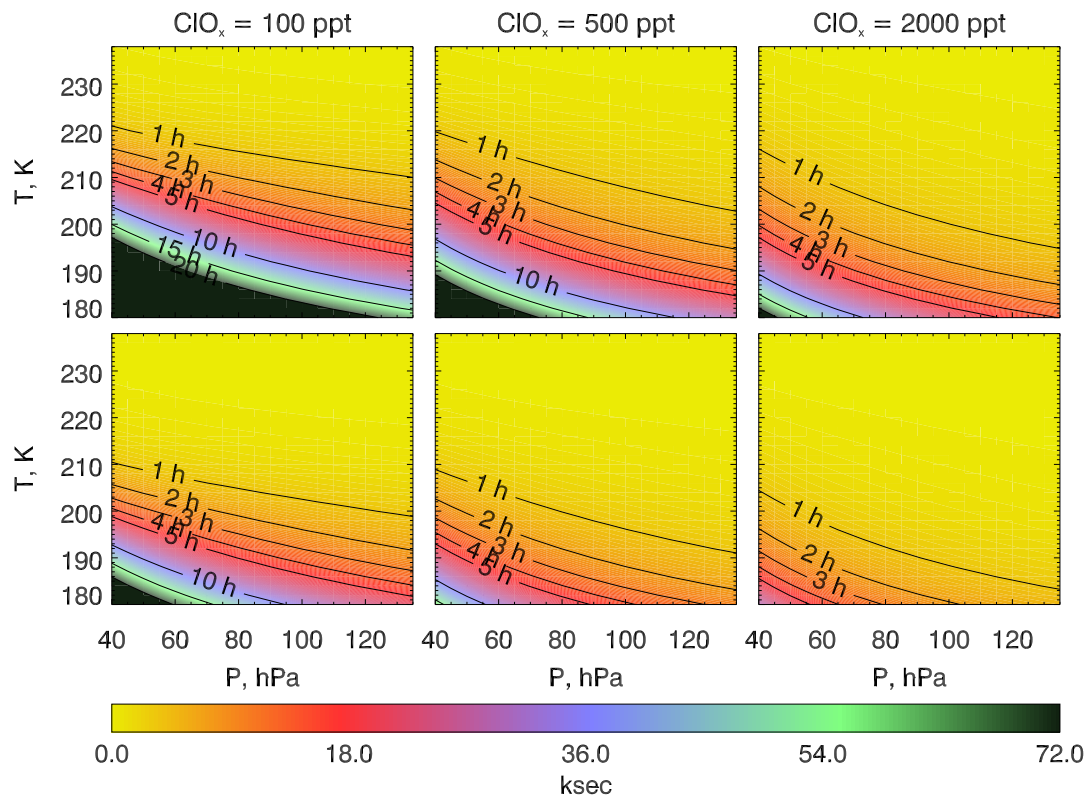

Fig. 7. Relaxation time of the $\mathrm{ClO} / \mathrm{Cl}_{2} \mathrm{O}_{2}$ system into thermal equilibrium $\left(\left[\mathrm{Cl}_{2} \mathrm{O}_{2}\right] /[\mathrm{ClO}]^{2}>0.8 K_{E Q}\right)$, as it depends on temperature and pressure for three different $\mathrm{ClO}_{\mathrm{x}}$ concentrations, assuming $[\mathrm{ClO}]=\left[\mathrm{ClO}_{\mathrm{x}}\right]$ and $\left[\mathrm{Cl}_{2} \mathrm{O}_{2}\right]=0$ at $t=0$. Results are shown for both the JPL 2002 equilibrium constant (top panels) and the equilibrium constant inferred from the EUPLEX data (bottom panels).

Temperature measurements were carried out by the Central Aerological Observatory, Russia, employing Rosemount sensors (estimating the maximum error to $\pm 0.6 \mathrm{~K}$ ), while static pressure was taken from the UCSE aircraft system. SZA is calculated using position and geometric altitude data provided by the onboard GPS system together with the exact time.

\section{Derivation of the $\mathrm{ClO} / \mathrm{Cl}_{2} \mathrm{O}_{2}$ equilibrium constant}

The equilibrium constant of Reaction (R1) can be inferred from observations using Eq. (1). However, this relation is valid only when $\mathrm{ClO}$ and $\mathrm{Cl}_{2} \mathrm{O}_{2}$ are in equilibrium, and the rate of dimer photolysis (R2) is zero. This is usually the case at night when the excess $\mathrm{ClO}$ monomer produced photochemically during daytime has relaxed back into thermal equilibrium. The relaxation time needed for the active chlorine species $\left(\mathrm{ClO}_{\mathrm{x}}=\mathrm{ClO}+2 \mathrm{Cl}_{2} \mathrm{O}_{2}\right)$ to go from the point where practically all $\mathrm{ClO}_{\mathrm{x}}$ is in the form of $\mathrm{ClO}$ to $\mathrm{ClO} / \mathrm{Cl}_{2} \mathrm{O}_{2}$ equilibrium strongly depends on temperature, pressure and $\mathrm{ClO}_{\mathrm{x}}$ concentration (Fig. 7). Measurements of these parameters are used to calculate the relaxation time for the EUPLEX and ENVISAT validation data points. Strictly, $\mathrm{ClO}$ and its dimer are assumed to be in equilibrium when the relaxation time calculated using the JPL 2002 equilibrium constant is smaller than the time elapsed since the dimer photolysis rate (with the rate constant $J$ parameterised as a function of zenith angle and altitude using $\mathrm{Cl}_{2} \mathrm{O}_{2}$ absorption cross sections according to Burkholder et al., 1990) fell below $10 \%$ of the thermal decomposition rate $\left(k_{b}\right.$ calculated using JPL 2002 recommendations for $K_{E Q}$ and $k_{f}$ ). The time in darkness is calculated along back trajectories based on ECMWF wind fields. Because this "strict" equilibrium criterion limits the data base to only a few points from three flights, a second, "soft" equilibrium criterion is installed that allows including more points. For this criterion, equilibrium is assumed when the relaxation time calculated using the new equilibrium constant inferred from our observations (cf. below) is smaller than the time elapsed since the dimer photolysis rate fell below $1 / 3$ of the thermal decomposition rate, which is not unrealistic given that relaxation into equilibrium usually starts well before sunset (cf. Fig. 6). With the soft equilibrium criterion, data from six flights qualify for the thermal equilibrium situation. For each data point obeying the soft but not the strict equilibrium criterion, a maximum equilibrium $\left[\mathrm{Cl}_{2} \mathrm{O}_{2}\right] /[\mathrm{ClO}]^{2}$ ratio is also computed given how far the amount of $\mathrm{ClO}_{\mathrm{x}}$ present would have progressed from an all monomer situation towards the JPL 2002 equilibrium during the time passed since $J<0.1 k_{b}$.

The temperature dependence of $K_{E Q}$ is given by the Van't Hoff equation:

$$
\frac{d \ln K}{d T}=\frac{\Delta H^{\theta}}{R T^{2}} \quad \text { or } \quad \frac{d \ln K}{d(1 / T)}=\frac{-\Delta H^{\theta}}{R} .
$$

If $\Delta H^{\theta}$ is assumed to be independent of $T$, integration yields:

$$
K_{E Q}=A \exp (B / T) \quad \text { with } \quad B=-\Delta H^{\theta} / R .
$$

The inferred values for $K_{E Q}$ are plotted against 1/T in Fig. 8 . Initially (Fig. 8a), least squares fits of $\ln \left(K_{E Q}\right)$ against $1 / T$ 

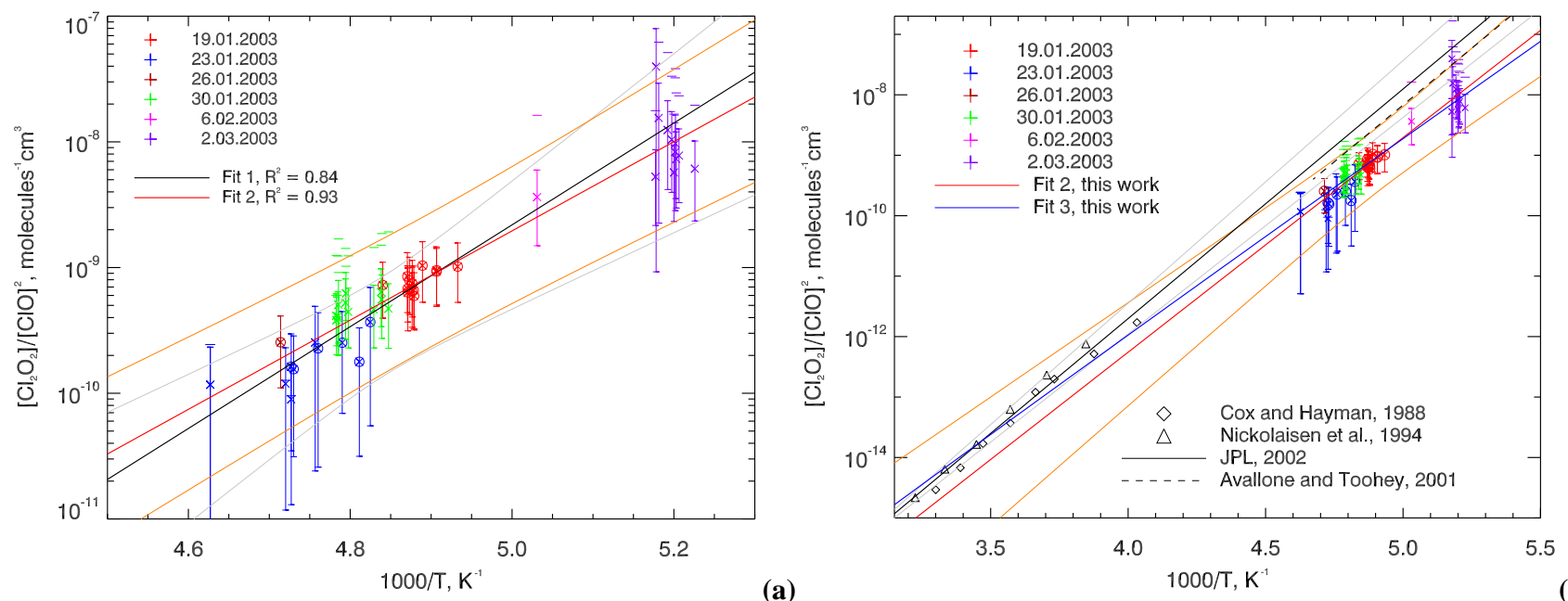

(b)

Fig. 8. (a) Van't Hoff plot of EUPLEX data for which thermal equilibrium can be assumed. Data points framed by a circle obey the strict equilibrium rule, horizontal bars above the soft rule points give the maximum equilibrium $\left[\mathrm{Cl}_{2} \mathrm{O}_{2}\right] /[\mathrm{ClO}]^{2}$ ratio for these data (see text for explanation). Fits 1 and 2 are linear least squares fits of $\ln \left(\left[\mathrm{Cl}_{2} \mathrm{O}_{2}\right] /[\mathrm{ClO}]^{2}\right)$ against $1 / T$ according to Eq. (3) for the strict equilibrium data and all data points, respectively. Uncertainty estimates (grey/orange) take into account error bars on the data and error estimates of the fitting parameters $(3 \sigma)$. (b) Expanded Van't Hoff plot from (a) with laboratory measurements and $K_{E} Q$ values proposed in the literature for comparison. Fit 2 is the same as in (a), fit 3 employs Eq. (4). Functions and parameters for all fits are summarised in Table 1.
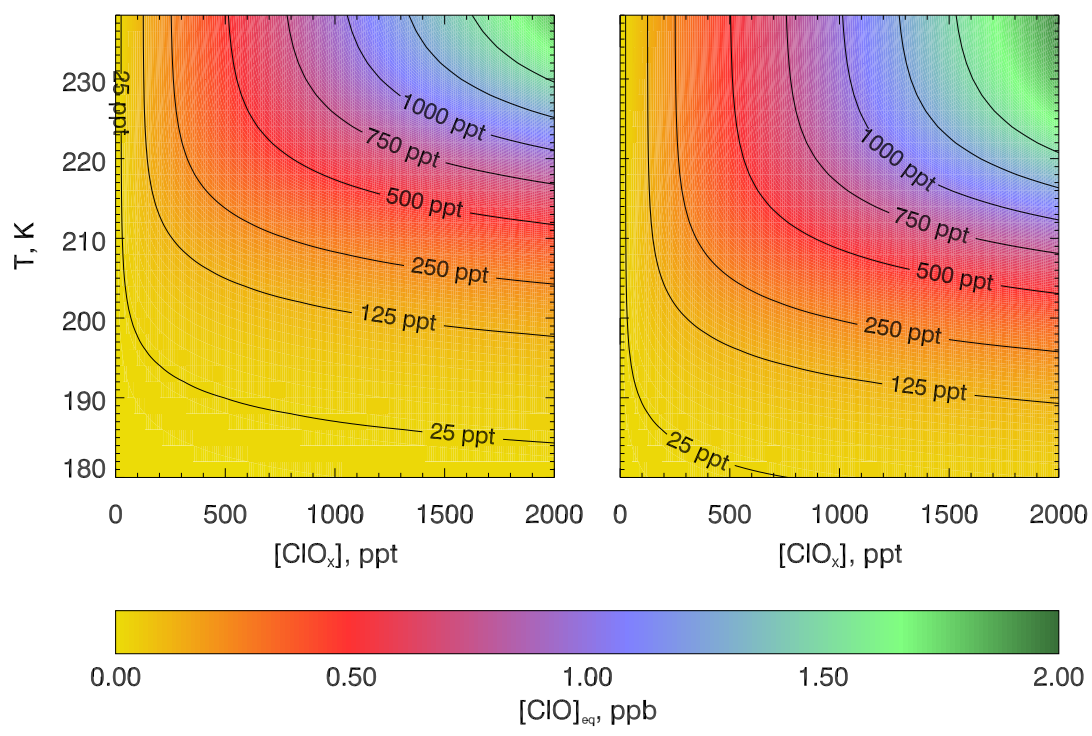

Fig. 9. Equilibrium $\mathrm{ClO}$ concentration as a function of temperature and $\mathrm{ClO}_{\mathrm{x}}$ for the $\mathrm{JPL} 2002$ equilibrium constant (left panel) and the equilibrium constant inferred from fit 2 in this study (right panel).

were carried out separately for both, the points satisfying the strict equilibrium and the soft equilibrium criteria. Because there are no points at temperatures below $200 \mathrm{~K}$ satisfying the "strict equilibrium" rule, the statistically more significant fit to "soft equilibrium" data was used in the following analysis, which is justified through the observation, that points obeying only the soft equilibrium criterion are not significantly lower (as would be expected if photolysis effects were still significant) than those obeying the strict one and the fits agree within uncertainty limits.

At stratospheric temperatures, $K_{E Q}$ derived from our observations lies below the JPL 2002 recommendation by a factor of 4 to 7 and below the estimate given by Avallone and Toohey (2001) by a factor of 2 to 4 (Fig. 8b). Irrespective of any potential errors in our $\mathrm{Cl}_{2} \mathrm{O}_{2}$ measurements discussed above, the notion that these two literature values 
Table 1. Functions for the $T$ dependence of $K_{E Q}$ fitted to observations in Fig. 8.

\begin{tabular}{ll}
\hline Fit & $K_{E Q}=$ \\
\hline JPL 2002 & $1.27 \times 10^{-27} \exp (8744 / T)$ \\
Fit 1: "strict" eq. criterion, Eq. (3) & $1.22 \times 10^{-29} \exp (9327 / T)$ \\
Fit 2: "soft" eq. criterion, Eq. (3) & $3.61 \times 10^{-27} \exp (8167 / T)$ \\
Fit 3: "soft" eq. criterion, Eq. (4b) & $5.47 \times 10^{-25}(T / 300)^{-2.29} \exp (6969 / T)$ \\
\hline
\end{tabular}

both overestimate $K_{E Q}$ is supported by the observation that the theoretical amount of $\mathrm{ClO}_{\mathrm{x}}$ inferred from our measured $\mathrm{ClO}$ would be as high as 7.2 and $4.3 \mathrm{ppb}$, respectively, for the JPL 2002 and Avallone and Toohey (2001) estimates of $K_{E Q}$. Even if all available chlorine was activated, such values are clearly larger than can be reconciled with the present day stratospheric chlorine loading (WMO, 2003). The reason for the obvious discrepancy of our observations and inferred $K_{E Q}$ with these studies can not be resolved at this time. As stated above, equilibrium may have been not fully established for some of our measurements, and the large uncertainty resulting from the various error sources does encompass the Avallone and Toohey (2001) estimate for $K_{E Q}$, which they state to be an upper limit. Previous observations of $\mathrm{ClO}$ and $\mathrm{Cl}_{2} \mathrm{O}_{2}$ (Stimpfle et al., 2004) also suggest a slightly lower value for $K_{E Q}$ compared to Avallone and Toohey (2001) at least at the lowest observed temperatures, but lie still above our inferred $K_{E Q}$. The agreement between the derived $K_{E Q}$ and a recent laboratory study using a completely independent method (Plenge et al., 2004b ${ }^{1}$ ) is very good given the uncertainties of both employed experimental techniques.

The discrepancy between the stratospheric observations and the laboratory studies on which the JPL 2002 recommendation is based (Cox and Hayman, 1988; Nickolaisen et al., 1994) is reduced, if we integrate the Van't Hoff equation under the assumption that $\Delta H^{\theta}$ depends linearly on $T$. In this case we obtain

$K_{E Q}=A T^{n} \exp \left(-\Delta H^{\theta 0} / R T\right)$,

which can be expressed in the more convenient form

$K_{E Q}=A^{\prime}(T / 300)^{n} \exp (B / T)$

with

$A^{\prime}=A \cdot 300^{n}$ and $B=-\Delta H^{\theta 0} / R$.

A three parameter fit of Eq. (4) through both our observations and the laboratory data, brings them to better agreement (fit 3 in Fig. 8b). Because the three fitting parameters in a function of this form are highly correlated, their individual uncertainty is rather large.

Reaction enthalpies do indeed depend on temperature, but this effect is small and negligible for most reactions. For the $\mathrm{ClO} / \mathrm{Cl}_{2} \mathrm{O}_{2}$ equilibrium, a recent study estimates the $T$ exponent $n=-0.29$ (Plenge et al., 2004b ${ }^{1}$ ). The temperature dependence implied by $n=-2.29$ is higher, although it still agrees within its uncertainty given by the fit. Another possible explanation for this effect is the formation of different isomers of $\mathrm{Cl}_{2} \mathrm{O}_{2}$, which has been suggested in numerous theoretical (Fangstrom et al., 1998; Golden, 2003; Han et al., 1998; Lee et al., 1992; Li and Ng, 1997; McGrath et al., 1990; Stanton et al., 1991; Zhu and Lin, 2003) and experimental (Jacobs et al., 1994; Müller and Willner, 1992; Plenge et al., 2004a; Schwell et al., 1996) studies on the stability of the three stable $\mathrm{Cl}_{2} \mathrm{O}_{2}$ isomers, namely chlorine peroxide $(\mathrm{ClOOCl})$, chloryl chloride $\left(\mathrm{ClClO}_{2}\right)$ and chlorine chlorite $(\mathrm{ClOClO})$. Slanina and Uhlík have presented calculations showing that the relative stabilities of the $\mathrm{Cl}_{2} \mathrm{O}_{2}$ isomers and hence the composition of the equilibrium isomeric mixture depends on temperature (Slanina and Uhlik, 1991b), and that this has direct effects on the temperature dependence of $K_{E Q}$ (Slanina, 1992; Slanina and Uhlik, 1991a). They present yet another functional form to extrapolate the laboratory observations of $K_{E Q}$ also resulting in a reduced value compared to the JPL 2002 recommendation at stratospheric temperatures (Slanina, 1992).

Regardless of any hypothetical physical explanation for the observed behaviour of the temperature dependence of $K_{E Q}$, it is obvious that the JPL 2002 recommendation for $K_{E Q}$ should be adjusted downwards. In the temperature range prevailing in the lower stratosphere, fits 2 and 3 to the observations yield very similar values, and any of the resulting functions (Table 1) can be used in atmospheric models. Fit 2 is used in the following, because it obeys the given JPL 2002 format for the temperature dependence of equilibrium constants and thus only the fitting parameters $A$ and $B$ need to be modified. The difference of this fit to JPL 2002 ranges from a factor 4 at $225 \mathrm{~K}$ to a factor 7 at $190 \mathrm{~K}$.

\section{Implications}

Figure 9 shows how changing $K_{E Q}$ from the JPL 2002 recommendation to the new value greatly increases predicted night-time $\mathrm{ClO}$ concentrations. However, the effect on ozone loss rates is expected to be small, because during sunlit hours, when ozone depleting catalytic cycles are effective, 


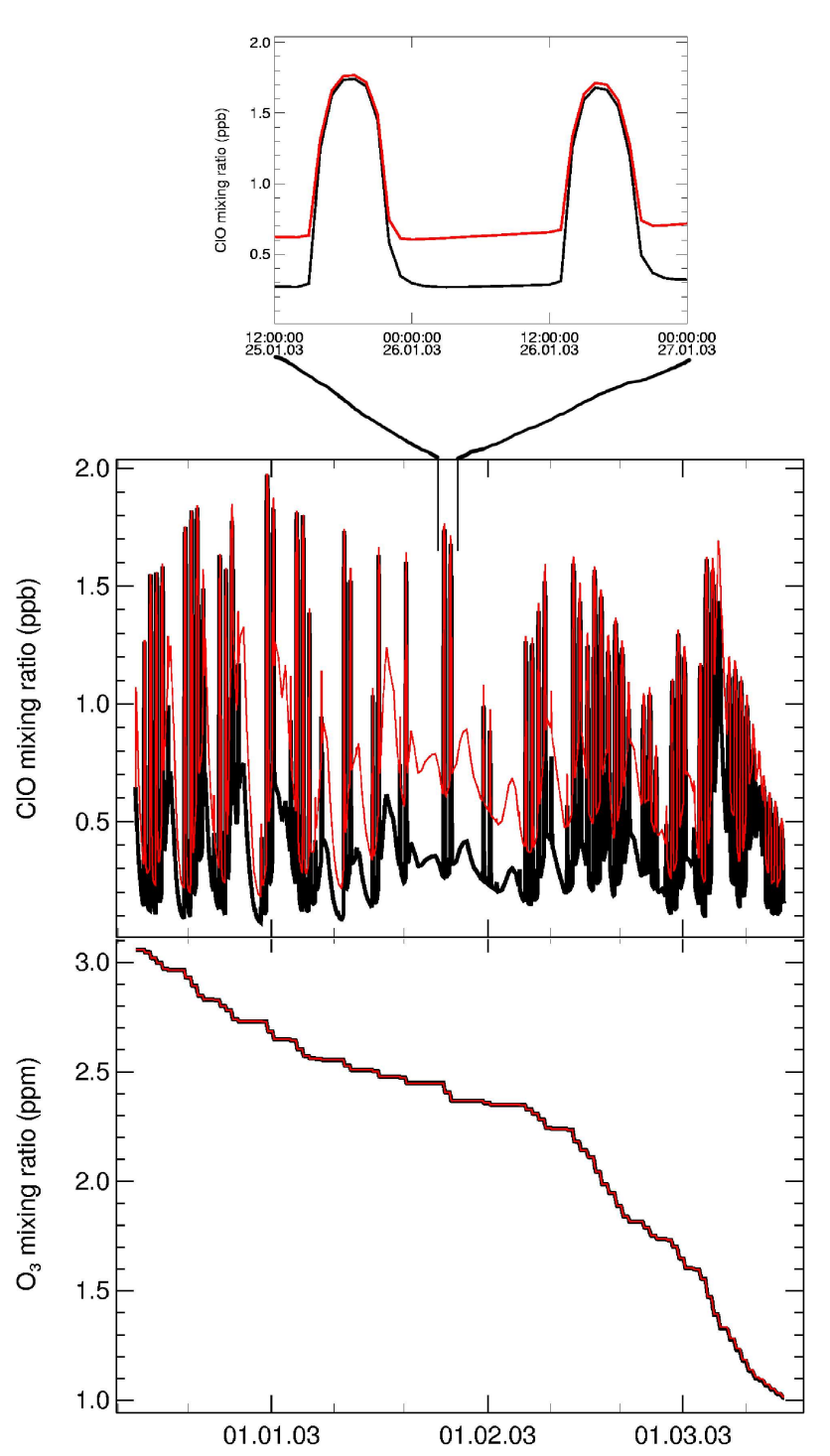

Fig. 10. Simulated $\mathrm{ClO}$ (top panels) and $\mathrm{O}_{3}$ (bottom panel) along a sample trajectory using $K_{E Q}$ values from JPL 2002 (black) and according to Fit 2 (red).

the $\mathrm{ClO}$ concentration is controlled almost entirely by the balance between the dimer formation Reaction (R1) and dimer photolysis (R2). This is confirmed by chemistry calculations using the CLaMS model (McKenna et al., 2002) along an example trajectory from 12 December 2002 to 15 March 2003 that remained in the vortex for the whole simulation period and exhibited particularly strong ozone depletion. The model was initialised from a 3-D CLaMS simulation performed for the winter, i.e. $3.2 \mathrm{ppb} \mathrm{Cl}_{\mathrm{y}}$ and $22 \mathrm{ppt} \mathrm{Br}_{\mathrm{y}}$ (Grooß et al., 2004). As Fig. 10 shows, using $K_{E Q}$ from fit 2 compared to JPL 2002 significantly alters the $\mathrm{ClO}_{\mathrm{x}}$ partitioning only at night. However, accumulated ozone loss over this period, also depicted in Fig. 10, is virtually unaffected.
A borderline case occurs under twilight conditions at large solar zenith angles, when there is still enough light for chemical ozone loss to occur but $\mathrm{ClO}$ is already appreciably affected by the $K_{E Q}$ re-evaluation. Under these conditions, the elevated $\mathrm{ClO}$ concentrations cause the rate of another strong ozone destroying catalytic cycle, the $\mathrm{ClO}-\mathrm{BrO}$ cycle (McElroy et al., 1986),

$$
\begin{aligned}
& \mathrm{ClO}+\mathrm{BrO} \rightarrow \mathrm{Cl}+\mathrm{Br}+\mathrm{O}_{2} \\
& \rightarrow \mathrm{Br}+\mathrm{OClO} \\
& \rightarrow \mathrm{BrCl}+\mathrm{O}_{2} \\
& \mathrm{BrCl}+\mathrm{h} v \rightarrow \mathrm{Br}+\mathrm{Cl} \\
& \mathrm{Br}+\mathrm{O}_{3} \rightarrow \mathrm{BrO}+\mathrm{O}_{2} \\
& \mathrm{Cl}+\mathrm{O}_{3} \rightarrow \mathrm{ClO}+\mathrm{O}_{2}
\end{aligned}
$$

to increase by promoting Reaction (5). The ClO-BrO cycle is the second most important catalytic cycle under polar conditions (e.g. Salawitch et al., 1993), and becomes unproportionally more important at large zenith angles because $\mathrm{BrCl}$ is photolysed at longer wavelength compared to $\mathrm{Cl}_{2} \mathrm{O}_{2}$ (Sander et al., 2003). To study the diurnal dependence of the partitioning between $\mathrm{ClO}$ and its dimer and the resulting ozone depletion due to both catalytic cycles, a 2-day simulation (1-3 February) for an air parcel at a constant location and temperature was performed. It was initialised with $22 \mathrm{ppt}$ $\mathrm{Br}_{\mathrm{y}}$ and $3.1 \mathrm{ppb} \mathrm{Cl}_{\mathrm{y}}$ and an almost complete chlorine activation of $88 \%$ as in the trajectory simulation explained above. For this case the ozone depletion rate and its contribution from the $\mathrm{ClO}-\mathrm{BrO}$ cycle (R5-R8) and the $\mathrm{ClO}$ dimer cycle (R1-R4) has been evaluated both for the equilibrium constant from fit 2 suggested here and from JPL 2002. Figure 11 shows the results for $60^{\circ} \mathrm{N}$ and $195 \mathrm{~K}$ temperature on the $500 \mathrm{~K}$ potential temperature level. At zenith angles between about $85^{\circ}$ and $95^{\circ}$, particularly just after sunrise when $\mathrm{ClO}$ is determined almost entirely by the thermal equilibrium, the choice of $K_{E Q}$ causes a significant change in ozone loss rates (Fig. 12). At zenith angles greater than $90^{\circ}$, enhanced ozone loss is observed which can be attributed to a faster rate of the $\mathrm{ClO}-\mathrm{BrO}$ catalytic cycle caused by the elevated $\mathrm{ClO}$ concentrations. At solar zenith angles less than $90^{\circ}$, the dimer cycle dominates ozone loss and the reduced concentration of $\mathrm{ClO}$ dimer caused by the equilibrium shift causes this cycle to proceed slower, resulting in less ozone loss (positive difference in $\mathrm{dO}_{3} / \mathrm{d} t$ in Fig. 12).

While we find here that the overall ozone loss is not strongly affected by the magnitude of $K_{E Q}$, a temperature dependent branching ratio of the $\mathrm{ClO}$ association reaction into different isomers could have a large impact. While the $\mathrm{ClOOCl}$ photolysis proceeds mainly according to Reaction (2) with only a minor proportion going back to two $\mathrm{ClO}$ radicals, the other two stable isomers, $\mathrm{ClClO}_{2}$ and $\mathrm{ClOClO}$, 


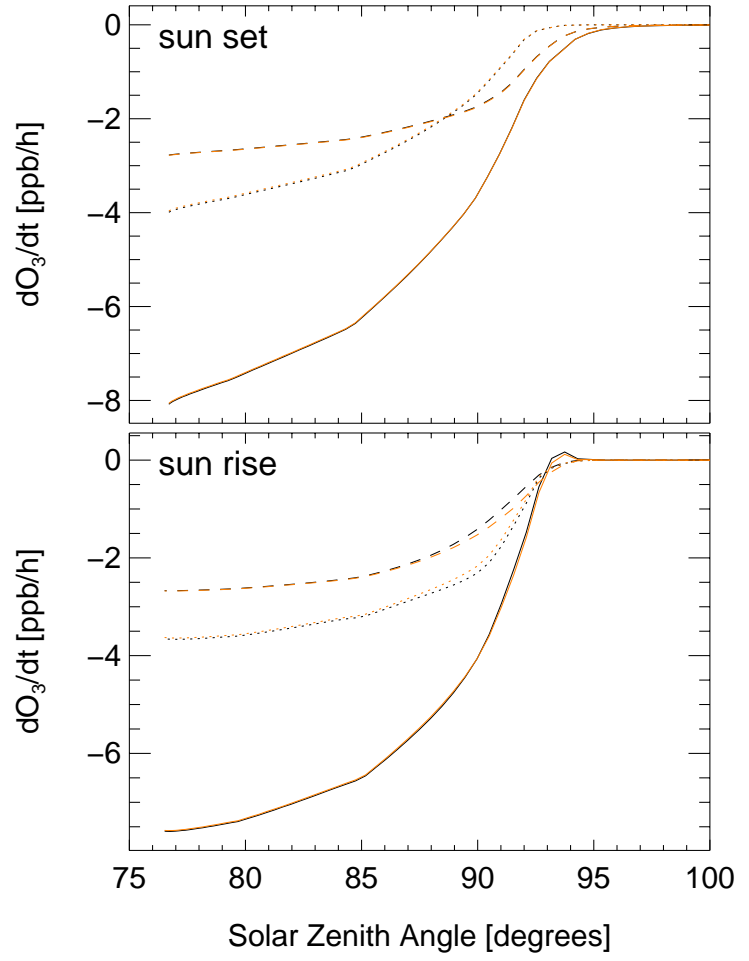

Fig. 11. Dependency of the overall ozone loss rate (solid lines) and ozone loss attributed to the $\mathrm{ClO}$-dimer (dotted lines) and $\mathrm{ClO}-\mathrm{BrO}$ (dashed lines) catalytic cycles on SZA for $K_{E Q}$ from JPL 2002 (black) and according to Fit 2 (red) at sunrise and sunset for $60^{\circ} \mathrm{N}$, $T=195 \mathrm{~K}$ on the $500 \mathrm{~K}$ potential temperature level.

could photolyse to different products, including $\mathrm{Cl}+\mathrm{OClO}$, where $\mathrm{OClO}$ in turn photolyses to $\mathrm{ClO}$ and an oxygen atom. As in this case the removal of one odd oxygen by the $\mathrm{Cl}$ radical is matched by the production of an oxygen radical, this results in a null cycle that does not destroy ozone. This means that if the presence of different isomers of $\mathrm{Cl}_{2} \mathrm{O}_{2}$ is indeed the correct explanation for the behaviour of the equilibrium constant, the consequence would be a reduced ozone loss in the $\mathrm{ClO}$ dimer cycle, especially at low temperatures.

\section{Conclusions}

We have presented simultaneous observations of $\mathrm{ClO}$ and its dimer $\left(\mathrm{Cl}_{2} \mathrm{O}_{2}\right)$. Based on these measurements we deduce the thermal equilibrium constant $K_{E Q}$ for the equilibrium between $\mathrm{ClO}$ and $\mathrm{Cl}_{2} \mathrm{O}_{2}$. Different parameterisations are given (Table 1) using the standard format used by the JPL evaluation panel (Sander et al., 2003) as well as a modified format that attempts to reconcile the field observations with available laboratory studies. All parameterisations predict much lower values for $K_{E Q}$ than recommended by JPL 2002. Using the lower $K_{E Q}$ value in the CLaMS chemistry model leads to enhanced ozone loss due to the $\mathrm{ClO}-\mathrm{BrO}$ cat-

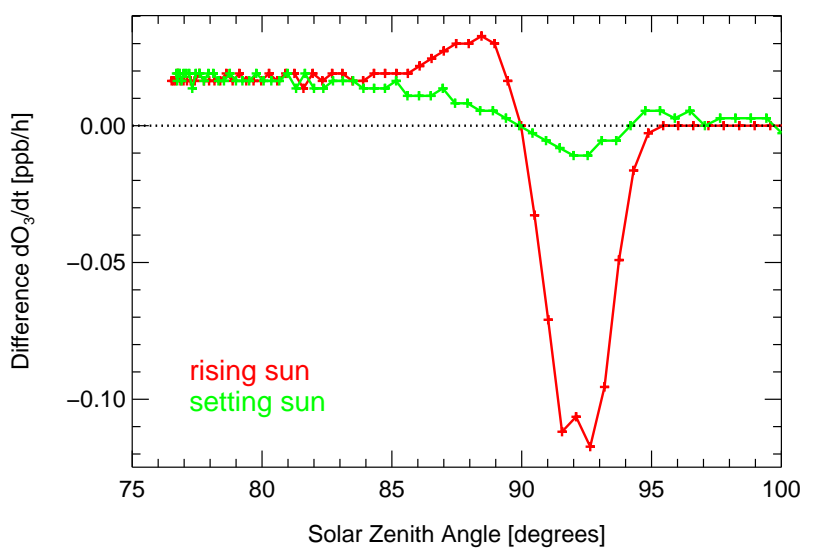

Fig. 12. Change of ozone loss rate induced by using $K_{E Q}$ according to Fit 2 instead of JPL 2002 recommended $K_{E Q}$. Shown is the difference of the solid lines in Fig. 11 (positive values of $\mathrm{dO}_{3} / \mathrm{d} t$ mean greater ozone loss for the JPL 2002 recommendation).

alytic cycle at zenith angles between $90^{\circ}$ and $95^{\circ}$ and reduced ozone loss between $85^{\circ}$ and $90^{\circ}$ due to a decrease in the rate of the $\mathrm{ClO}$ dimer cycle. However, these changes are not significant in the context of the overall ozone loss over time periods of several days or longer.

To further reduce the uncertainty of the estimate given for $K_{E Q}$, more simultaneous measurements of $\mathrm{ClO}$ and $\mathrm{Cl}_{2} \mathrm{O}_{2}$ are desirable, especially just before sunrise, when the $\mathrm{ClO} / \mathrm{Cl}_{2} \mathrm{O}_{2}$ equilibrium is well established. The formation of different isomers of $\mathrm{Cl}_{2} \mathrm{O}_{2}$ as one possible explanation for the observed behaviour and the potential impact on ozone loss warrants further studies on this issue.

Acknowledgements. The authors are grateful to MDB and the crew of the M-55 Geophysica for their support during the campaigns, to Genrich Shur for providing temperature data, to H. Schlager from DLR Oberpfaffenhofen, T. Peter and G. Koch from ETH Zürich and R. Salawitch from JPL for their assistance in flight planning, and to ECMWF for meteorological analyses. We thank D. Toohey for valuable comments on the manuscript. VINTERSOL-EUPLEX is funded through the EC grant EUK2-CT-2001-00119. We acknowledge the HGF Vernetzungsfond, the Bundesministerium für Bildung und Forschung (BMBF) and ESA for funding of the ENVISAT-Validation flights and instrument integration costs.

Edited by: K. S. Carslaw

\section{References}

Avallone, L. M. and Toohey, D. W.: Tests of halogen photochemistry using in situ measurements of $\mathrm{ClO}$ and $\mathrm{BrO}$ in the lower polar stratosphere, J. Geophys. Res.-A, 106 (D10), 10 411-10 421, 2001.

Brune, W. H., Anderson, J. G., and Chan, K. R.: Insitu Observations of $\mathrm{ClO}$ in the Antarctic - ER-2 Aircraft Results From $54^{\circ} \mathrm{S}$ to $72^{\circ}$ S Latitude, J. Geophys. Res.-A, 94(D14), 16 649-16663, 1989. 
Cox, R. A. and Hayman, G. D.: The Stability and Photochemistry of Dimers of the ClO Radical and Implications For Antarctic Ozone Depletion, Nature, 332 (6167), 796-800, 1988.

Fangstrom, T., Edvardsson, D., Ericsson, M., Lunell, S., and Enkvist, C.: Density functional study of chlorine-oxygen compounds related to the $\mathrm{ClO}$ self-reaction, Int. J. Quantum Chem., 66 (3), 203-217, 1998.

Glatthor, N., von Clarmann, T., Fischer, H., Funke, B., Grabowski, U., Höpfner, M., Kellmann, S., Kiefer, M., Linden, A., Milz, M., Steck, T., Stiller, G. P., Mengistu Tsidu, G., and Wang, D.Y.: Spaceborne $\mathrm{ClO}$ observations by the Michelson Interferometer for Passive Atmospheric Sounding (MIPAS) before and during the Antarctic major warming in September/October 2002, J. Geophys. Res., 109(D11), doi:10.1029/2003JD004440, 2004.

Golden, D. M.: Reaction $\mathrm{ClO}+\mathrm{ClO} \rightarrow$ products: Modeling and parameterization for use in atmospheric models, Int. J. Chem. Kinet., 35 (5), 206-211, 2003.

Grooß, J. U., Günther, G., Müller, R., Konopka, P., Bausch, S., Schlager, H., Volk, C. M., and Toon, G. C.: Simulation of denitrification and ozone loss for the Arctic winter 2002/03, Atmos. Chem. Phys. Discuss., 4, 8069-8101, 2004,

SRef-ID: 1680-7375/acpd/2004-4-8069.

Han, Y. K., Kim, K. H., Lee, Y. S., and Baeck, K. K.: Energies and structures of isomers of $\mathrm{Cl} 2 \mathrm{O} 2$ calculated by density functional methods, Theochem-J. Mol. Struct., 431 (1-2), 185-189, 1998.

Horowitz, A., Crowley, J. N., and Moortgat, G. K.: TemperatureDependence of the Product Branching Ratios of the ClO SelfReaction in Oxygen, J. Phys. Chem., 98 (46), 11924-11930, 1994.

Jacobs, J., Kronberg, M., Muller, H. S. P., and Willner, H.: An Experimental-Study On the Photochemistry and Vibrational Spectroscopy of 3 Isomers of $\mathrm{Cl}_{2} \mathrm{O}_{2}$ Isolated in Cryogenic Matrices, J. Am. Chem. Soc., 116 (3), 1106-1114, 1994.

Lee, T. J., Rohlfing, C. M., and Rice, J. E.: An Extensive Abinitio Study of the Structures, Vibrational-Spectra, Quadratic ForceFields, and Relative Energetics of 3 Isomers of $\mathrm{Cl}_{2} \mathrm{O}_{2}$, J. Chem. Phys., 97 (9), 6593-6605, 1992.

Li, W. K. and Ng, C. Y.: Gaussian-2 ab initio study of isomeric $\mathrm{Cl}_{2} \mathrm{O}_{2}$ and $\mathrm{Cl}_{2} \mathrm{O}_{2}+$ and their dissociation reactions, J. Phys. Chem. A, 101 (2), 113-115, 1997.

McElroy, M. B., Salawitch, R. J., Wofsy, S. C., and Logan, J. A.: Reductions of Antarctic Ozone Due to Synergistic Interactions of Chlorine and Bromine, Nature, 321 (6072), 759-762, 1986.

McGrath, M. P., Clemitshaw, K. C., Rowland, F. S., and Hehre, W. J.: Structures, Relative Stabilities, and Vibrational-Spectra of Isomers of $\mathrm{Cl}_{2} \mathrm{O}_{2}$ - the Role of the Chlorine Oxide Dimer in Antarctic Ozone Depleting Mechanisms, J. Phys. Chem., 94 (15), 6126-6132, 1990.

McKenna, D. S., Grooß, J. U., Günther, G., Konopka, P., Müller, R., Carver, G., and Sasano, Y.: A new Chemical Lagrangian Model of the Stratosphere (CLaMS) - 2. Formulation of chemistry scheme and initialization, J. Geophys. Res., 107, doi:10.1029/2000JD000113, 2002.

Molina, L. T. and Molina, M. J.: Production of $\mathrm{Cl}_{2} \mathrm{O}_{2}$ From the Self-Reaction of the ClO Radical, J. Phys. Chem., 91 (2), 433436, 1987.

Müller, H. S. P. and Willner, H.: Synthesis and Properties of Chloryl Chloride, $\mathrm{ClClO}_{2}$, Inorg. Chem., 31 (12), 2527-2534, 1992.

Nickolaisen, S. L., Friedl, R. R., and Sander, S. P.: Kinetics and
Mechanism of the $\mathrm{ClO}+\mathrm{ClO}$ Reaction - Pressure and Temperature Dependences of the Bimolecular and Termolecular Channels and Thermal-Decomposition of Chlorine Peroxide, J. Phys. Chem., 98 (1), 155-169, 1994.

Pierson, J. M., McKinney, K. A., Toohey, D. W., Margitan, J., Schmidt, U., Engel, A., and Newman, P. A.: An investigation of $\mathrm{ClO}$ photochemistry in the chemically perturbed arctic vortex, J. Atmos. Chem., 32 (1), 61-81, 1999.

Plenge, J., Flesch, R., Kühl, S., Vogel, B., Müller, R., Stroh, F., and Rühl, E.: Ultraviolet Photolysis of the ClO Dimer, J. Phys. Chem., 108, 4859-4863, 2004a.

Ricaud, P., Lefèvre, F., Berthet, G., et al.: Chlorine activation studies from the ODIN satellite measurements: the arctic and antarctic cases, in: Quadrennial Ozone Symposium, edited by: Zerefos, C. S., Kos, Greece, 1032, 2004.

Salawitch, R. J., Wofsy, S. C., Gottlieb, E. W., Lait, L. R., Newman, P. A., Schoeberl, M. R., Loewenstein, M., Podolske, J. R., Strahan, S. E., Proffitt, M. H., Webster, C. R., May, R. D., Fahey, D. W., Baumgardner, D., Dye, J. E., Wilson, J. C., Kelly, K. K., Elkins, J. W., Chan, K. R., and Anderson, J. G.: Chemical Loss of Ozone in the Arctic Polar Vortex in the Winter of 1991-1992, Science, 261 (5125), 1146-1149, 1993.

Sander, S. P., Friedl, R. R., Golden, M. M., Kurylo, M. J., Huie, R. E., Orkin, V. L., Moortgat, G. K., Ravishankara, A. R., Kolb, C. E., Molina, M. J., and Finlayson-Pitts, B. J.: Chemical Kinetics and Photochemical Data for Use in Atmospheric Studies, in: Evaluation Number 14, Jet Propulsion Laboratory, Pasadena, 2003.

Schwell, M., Jochims, H. W., Wassermann, B., Rockland, U., Flesch, R., and Rühl, E.: Ionization energies of $\mathrm{ClO}$ and $\mathrm{Cl}_{2} \mathrm{O}_{2}$, J. Phys. Chem., 100 (24), 10 070-10 075, 1996.

Slanina, Z.: Dimerization Equilibrium-Constant For the ClO Radical - State-of-the-Art Wide-Temperature-Interval Thermodynamics of Species Related to Ozone Depleting, Thermochim. Acta, 196 (2), 467-475, 1992.

Slanina, Z. and Uhlik, F.: An Estimation of Dimerization Energetics of the ClO Radical, Chem. Phys. Lett., 182 (1), 51-56, 1991a.

Slanina, Z. and Uhlik, F.: Temperature-Dependence of the Gibbs Energy Ordering of Isomers of $\mathrm{Cl}_{2} \mathrm{O}_{2}$, J. Phys. Chem., 95 (14), 5432-5434, $1991 \mathrm{~b}$.

Stanton, J. F., Rittby, C. M. L., Bartlett, R. J., and Toohey, D. W.: Low-Lying Isomers of the Chlorine Oxide Dimer - a TheoreticalStudy, J. Phys. Chem., 95 (6), 2107-2110, 1991.

Stimpfle, R. M., Wilmouth, D. M., Salawitch, R. J., and Anderson, J. G.: First measurements of $\mathrm{ClOOCl}$ in the stratosphere: The coupling of $\mathrm{ClOOCl}$ and $\mathrm{ClO}$ in the Arctic polar vortex, J. Geophys. Res., 109, doi: 10.1029/2003JD003811, 2004.

von Clarmann, T., Wetzel, G., Oelhaf, H., FriedlVallon, F., Linden, A., Maucher, G., Seefeldner, M., Trieschmann, O., and Lefevre, F.: $\mathrm{ClONO}_{2}$ vertical profile and estimated mixing ratios of $\mathrm{ClO}$ and $\mathrm{HOCl}$ in winter arctic stratosphere from Michelson interferometer for passive atmospheric sounding limb emission spectra, J. Geophys. Res.-A, 102(D13), 16 157-16168, 1997.

WMO Scientific Assessment of Ozone Depletion: 2002, WMO Report No. 47, World Meteorological Organization, Switerland, 2003.

Zhu, R. S. and Lin, M. C.: Ab initio studies of ClOx reactions, IV. Kinetics and mechanism for the self-reaction of $\mathrm{ClO}$ radicals, J. Chem. Phys., 118 (9), 4094-4106, 2003. 